Ath-Thariq, No. 01, Vol. 02 Juli-Desember 2017

\title{
AL HIJÂMAH SEBAGAI WASILAH DAKWAH
}

\author{
DEWI MUSTIKA \\ Institut Agama Islam Negeri (IAIN) Metro \\ Jl. Kihajar Dewantara 15A Iring Mulyo, Metro Timur, Kota Metro. \\ e-mail:mtcistimewa@gmail.com
}

\begin{abstract}
ABSTRAK
The teaching of the heavens (Islam) has been earthed through the angel Gabriel to the Prophet Muhammad sallallaahu 'alayhi wa Salam. With the derivation of the Holy Qur'an as a source of guidance, guidance, and strength for Muslims throughout the world. Through the Qur'an and Sunnah of the Prophet, Islam has given a teaching to man towards a healthy life both inward and inward. Not a few hadiths of Rasulullah SAW that contain medical values that we need to emulate today in the field of Islamic medicine. Among the words of the Prophet sallallaahu 'alayhi wa Salam commanded the ummah to berbekam. The research method that the writer uses is analytical descriptive method, with library research, in this research only described some concept of Rasulullah implicit in books of hadith that peel health problem, the work of scholars and medical experts. Then the author of the analysis by synergizing the methods and concepts of modern medicine today. Hope the Muslims can return to the treatment given by the Apostle which is loaded with the values of da'awi namely the Divine based medicine, ilmiyah and alamyah in this century. This research is still in the form of a global depiction, so it still requires in-depth and detailed assessment in its subtans. So that later could really become enlightenment for the Muslims in living this life.
\end{abstract}

Keywords: Al Hijamah, Da'wa and Health 


\section{A. PENDAHULUAN}

Ajaran Islam yang berkembang dibawah pimpinan Nabi Muhammad Shallallahu Alaihi wa Sallam, bukan hanya semata-mata sebuah teologi, tetapi memiliki landasan praktikal. Dalam implementasinya, ajaran Islam banyak didasarkan pada Sunnah Nabi Shallallahu Alaihi wa Sallam, yang merupakan kerangka berpikir bagi tindakan seorang muslim. Dengan meniru apa yang dilakukan Nabi Muhammad Shallallahu Alaihi wa Sallam. Ketika ia berhadapan dengan orang sakit, timbul yang saat ini dikenal pengobatan cara Nabi (AtThibb Al-Nabawi). ${ }^{1}$ Berkaitan dengan hal itu salah satu cara yang digunakan oleh Nabi dalam hal kesehatan yaitu sesuai dengan haditsnya dari Ibnu Abbas ra :

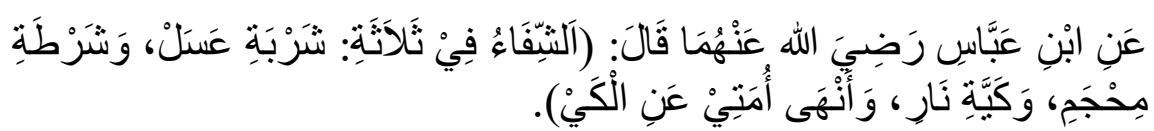

Artinya: "Kesembuhan itu terletak pada tiga hal, yakni minum madu, sayatan alat bekam, dan 'kay' dengan api, sesungguhnya aku melarang umatku dari 'kay'2" (Shohihu al-Bukhori, Ath-Thibb, Juz 1, hal. 5680)

Perintah berbekam itu berbeda-beda, sesuai dengan perbedaan zaman, tempat dan karakter. Ternyata sampai sekarang ini banyak sekali orang muslim yang belum pernah dibekam. Kenyataan ini sungguh memprihatinkan, sebab bekam sudah dikenal ribuan tahun yang lalu, bahkan sejak zaman Nabi Musa as, dan berkembang keseluruh dunia hingga saat ini.

Di Indonesia bekam sudah sering dipakai untuk pengobatan dengan beberapa nama seperti canduk, canthuk, kop, cupping, mambakan dan lain sebagainya. Bekam merupakan terjemahan dari hijamah dari kata al hajmu, yang berarti pekerjaan membekam. Al hajmu berarti menghisab atau menyedot. Sehingga hijamah atau bekam diartikan sebagai peristiwa penghisapan darah dengan alat menyerupai tabung, serta mengeluarkanya dari permukaan kulit dengan penyayatan yang kemudian ditampung didalam gelas. Dilihat sepintas, tampaknya pengobatan dengan metode bekam tidak memberi manfaat apaapa, bahkan terkesan kuno, irasional, dan mengada-ngada. Apabila dibandingkan dengan pengobatan medis modern yang memakai obat-obatan sintetik serta pembedahan yang memerlukan biaya mahal. Bekam lebih praktis, tanpa efek samping, murah dan bisa mengatasi banyak penyakit yang tidak bisa ditangani oleh kedokteran modern.

Memang, sekarang ini segala sesuatu yang berbau "Barat" yang didominasi orang Nasrani dan Yahudi tampak indah menyenangkan dan menyembuhkan. Ini memang usaha mereka untuk menjauhkan kaum muslimin dari kitab-Nya Al Qur'an. Mereka mengetahui bahwa apabila kaum

${ }^{1}$ Aliah B. Purwakania Hasan, Pengantar Psikologi Kesehatan Islami, Rajawali Pres, Jakarta, 2008, hal.19

2 Kay adalah cara pengobatan dengan memakai bahan tumbuhan yang dibakar pada titik tertentu dari tubuh, sehingga daya panas yang ditimbulkan menembus permukaan kulit, otot, fascia dan jaringan dibawahnya hingga menimbulkan reaksi pengobatan. 
muslimin berpegang teguh pada ajara-Nya, pastilah mereka akan jaya dan menguasai dunia, seperti yang telah dialami umat Islam pada abad 8 hingga 12 Masehi, dimana saat itu ilmu kedokteran berkembang menguasai daratan Eropa, sehingga muncullah dokter-dokter muslim dengan kedokteran Islamnya, seperti Ali Abbas Al Majusi, Abu Bakar Ar Rozi, Al Biruni, Ibnu Sina, Az Zahrowi, Ibnu Maimun, Ibnu Qayyim Al Jauziyyah dan lain-lainya. Padahal saat itu kaum Nasrani sendiri sulit untuk meningkatkan keilmuannya, karena terhambat dengan pendapat gereja yang menyebut pengetahuan modern bertentangan dengan Bibel. Sehingga yang berbeda dengan Bibel dianggap menentang Bibel.

Sebab walaupun dalam Bibel tidak ada yang menghukum para ilmuan, namun pada prakteknya banyak ilmuan yang bersebrangan dengan gereja. Bahkan orang yang menentang pendapat gereja akan dihukum seperti yang dilakukan pada Galille yang dituntut hanya karena ia mengikuti penemuan Coppericus tentang peredaran bumi. Galille kemudian dihukum dengan alasan menafsirkan Bibel secara keliru. Inilah yang menyebabkan kaum Nasrani beramai-ramai meninggalkan agama mereka, sehingga mereka bisa memajukan sain dan kedokteran. Sementara saat ini, banyak kaum muslimin yang meninggalkan ajarannya, termasuk dalam bidang kedokteran. Umat Islam hanya berkutat pada ibadah harian, shalat, puasa dan haji, sehingga sain dan kedokteran dikuasai sepenuhnya oleh orang-orang Nasrani dan Yahudi, agar umat Islam tertinggal dari segala bidang, termasuk dalam bidang kedokteran.

Kaum muslimin jarang sekali yang mau mendalami ilmu kedokteran warisan Nabi Shallallahu Alaihi wa Sallam yang sangat lengkap. Diantara sebagian kedokteran warisan Nabi yang dilupkan itu adalah bekam. Bahkan mendengarpun belum pernah. Malahan ilmu bekam diserahkan kedunia Barat, sehingga mereka melakukan penelitian dan pembuktian terus-menerus, yang akhirnya mereka terapkan dalam kehidupan sehari-hari, walaupun mereka tidak menamakannya bekam.

Tetapi tetap memakai prinsip kerja bekam, menyedot darah dan mengumpulkannya, kemudian mengelurkannya tentunya dengan teknik dan teknologi canggih. Hingga muncullah ahli bekam Barat, seperti DR. Michael Reed Gach dari Caalifornia dengan bukunya Potent Poins, a Guide ti Self Care for Common Ailments (Titik-titik Berkhasiat sebagai Panduan Perawatan Diri dan Pengobatan Penyakit yang Umum), atau penelitian Kohler D dengan bukunya The Connective Tissue as The Physical Medium for Conduction of Healing Energy in Cupping Therapeutic Method (Jaringan Ikat sebagai Media Fisik untuk Menghantarkan Energi Pengobatan Dengan Bekam) atau tulisan Thomas W. 
Anderson yang berjudul 100 Diseases Treated by Cupping Method "100 Penyakit yang Dapat Diobati Dengan Bekam". ${ }^{3}$

Ketika kaum muslimin mengetahui hal ini, mereka terheran-heran dan mengagung-agungkan bahwa itulah metode pengobatan Barat yang canggih. Padahal, ketahuilah itu adalah ilmu yang mereka tinggalkan dan diserahkan kepada orang-orang Barat, seperti yang disampaikan Imam Syafi'i yang menyayangkan keteledoran kaum muslimin terhadap ilmu kedokteran. Beliau mengatakan :

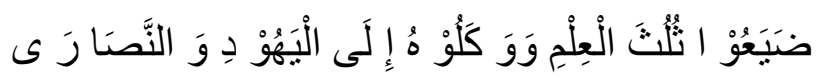

"Mereka (kaum muslimin) mengabaikan sepertiga ilmu dan menyerahkannya kepada orang-orang Yahudi dan Nasrani."

\section{B. AL-HIJAMAH}

Al hijamah atau bekam mempunyai beberapa sebutan, seperti : canduk, chanthuk, kop atau mambakan. Di Eropa disebut cupping dan fire bottle. Dalam bahasa Mandarin disebut $\mathrm{Pa}$ Hou Kuan. Dalam bahasa Arap disebut hijamah, dari kata $A l$ Hajmu yang berarti pekerjaan, yaitu mebekam. Al Hijamah berarti ahli bekam. Al hajmu berarti menghisab atau menyedot. Sedangkan al Mihjam atau Al Mihjamah merupakan alat untuk membekam, yang berupa gelas untuk menampung darah yang dikeluarkan dari kulit, atau gelas untuk mengumpulkan darah hijamah.

Maka secara bahasa, bekam berarti menghisab. Menurut istilah, bekam berarti peristiwa penghisapan kulit, penyayatan dan mengeluarkan darahnya dari permukaan kulit, yang kemudian ditampung didalam gelas. berikut :

Dalam kitab-kitab Arab, memberikan pengertian tantang bekam sebagai

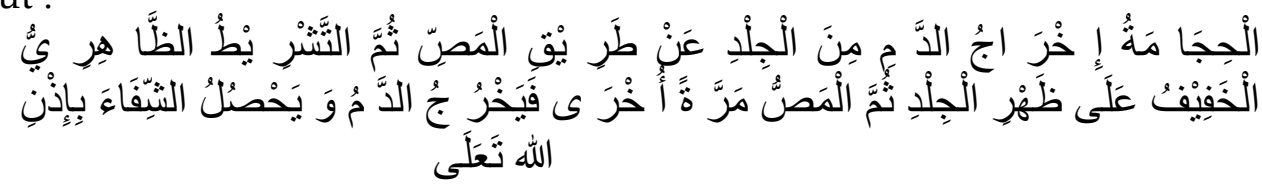

(Bekam adalah mengeluarkan darah dari kulit dengan cara menghisab, kemudian penyayatan ringan pada permukaan kulit, kemudian dilakukan penghisapan lagi agar darah bisa keluar dan menimbulkan kesembuhan dengan izin Allah Ta'ala).

Dengan demikian, proses pengobatan bekam melalui tiga peristiwa :

1. Penghisapan

2. Penyayatan

3. Pengeluaran darah

Di sini yang penting adalah bahwa pengeluaran darah dilakukan dengan penyayatan (mash) dengan pisau atau benda tajam lain, bukan penusukan dengan jarum atau dengan benda runcing. Luka karena sayat mengakibatkan

${ }^{3}$ Syihab Al Badri Yasin, Al Hijamah Sunnatun Nabawiyyah wa Mu'jizatun Thibbiyyah, Al Qowam: Jakarta, 1422 H/2001M) h. 1

Al Hijâmah Sebagai Wasilah Dakwah

Dewi Mustika 
pinggir lukanya tajam dan rata, dasarnya sempit, dan lukanya lebih lebar. Sehingga lebih mudah diberi disinfektan dan mudah sembuh.

Selain itu, luka sayat pada bekam hanya mengenai pembuluh darah kecil (kapiler) sehingga darah yang keluar adalah darah kapiler. Sedangkan luka tusuk mempunyai ukuran lubang masuk yang lebih kecil daripada dalamnya. Luka jenis ini dapat menimbulkan tetanus. Selain itu luka tusuk dapat menimbulkan luka diorgan-organ yang lebih dalam atau dipembuluh darah. Maka prinsipnya, bekam adalah pengobatan dengan cara menghisab permukaan kulit, sehingga darah dan segala sesuatu yang berada dibawah kulit akan ikut tersedot dan membanjiri daerah yang dihisab tersebut, dan terjadilah fenomena pengumpulan darah.

Ada beberapa cara untuk menghisab yakni cara yang asli dan tradisional adalah dengan memakai panas atau api yang dimasukkan dalam tabung, sehingga dapat menghisab kulit. Tabung yang dipakai berupa tabung kaca, gelas, bambu, tanduk binatang, bebatuan dan sebagainya. Para tabib zaman dulu, selain dengan api, mereka juga memakai herbal yang dipanaskan, sehingga panasnya dapat menghisab kulit dan herbal yang dipakai bermacammacam, dinegara-negara Arab memakai habbatus sauda', 'ud hindi atau qasthul bahri, jummar, zanzanbil, tamr dan lain-lainnya. Sedangkan di Negara China memakai Herba Ephedrae, Herba Serissae, Myrrha, akar Angelicae Pubescentis, Gantianae Macrophyllae, Follium Artemisiane Argy, dan lain-lain. Ada pula jenis bekam yang disertai pengeluaran darah, sehingga darah keluar dari kulit disebut dengan bekam damiyah, bekam rutbah atau bekam basah.

Ada yang tanpa pengeluaran darah, yakni darah cukup mengumpul dibawah kulit saja disebut dengan jaffah atau bekam kering. Bekam kering dipakai di China, Jepang dan sebagian negara Eropa dan Amerika. Sedangkan di Arab dipakai bekam basah. Pemilihan Jenis bekam ini tergantung dari tujuan pengobatan itu sendiri.

\section{HADITS-HADITS TENTANG AL HIJAMAH}

Al hijamah, walaupun bukan urusan ibadah langsung kepada Allah Subhanahu Wata'ala, namun banyak disinggung Rasulullah. Tujuan Rasulullah Shallallahu Alaihi wa Sallam, menyampaikan hadits tentang bekam adalah:

1. Hadits-hadits Tentang Keutamaan Bekam

a. Dari Said bin Jubair, dari Ibnu Abbas, Rasulullah bersabda :

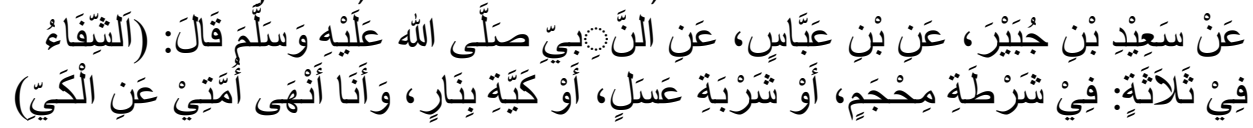

“Dari Said bin Jubair, dari Ibnu Abbas, dari Rasulullah Shallallahu 'alaihi wa sallam bersabda: "Kesembuhan itu ada dalam tiga hal yaitu, sayatan dengan bekam, minum madu dan kay. Namun aku melarang umatku 
melakukan kay."

Dalam hadits lain Nabi mengizinkan sahabat melakukan kay, seperti pada Sa'ad bin Ubaidah dan Ubay bin Ka'ab.

b. Dalam Sunan Ibnu Majah,

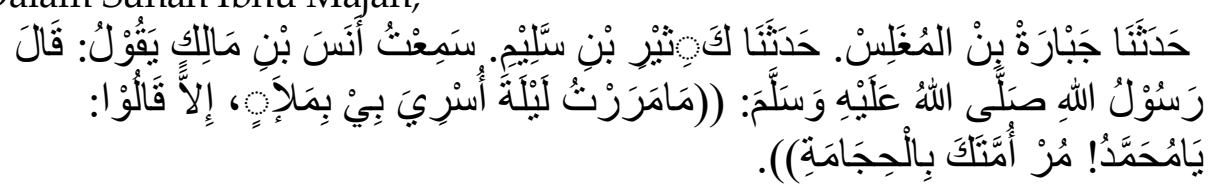

“Dari hadits Jabaroh bin Mughollis (seorang perowi dho'if), dari Katsir bin Salim, ia berkata aku mendengar Anas bin Malik berkata : Rasulullah Shallallahu 'alaihi wa sallam bersabda : "Aku tidak berjalan dihadapan sekelompok malaikat pada malam ketika aku di isra'kan, kecuali mereka berkata : wahai Muhammad perintahkanlah umatmu untuk berbekam. ${ }^{\prime \prime}$

2. Hadits-hadits yang Berkaitan dengan Tampat-tempat yang Baik untuk di Bekam.

a. Hadits yang diriwayatkan oleh Bukhari

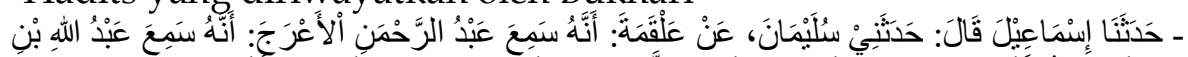

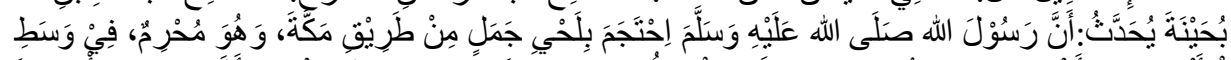

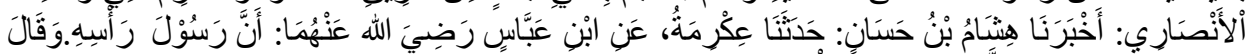

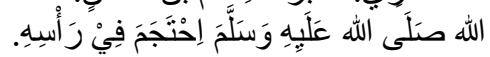

"Ismail berbicara kepada kami ia berkata : menceritakan kepada Sulaiman dari Al Qomah : "Sesungguhnya dia telah mendengar Abdurrahman al A'raj: "Sesungguhnya dia telah mendengar Abdullah bin Buhainah berbicara : "Bahwasannya Rasulullah telah berbekam didaerah Jamal yakni daerah perjalanan menuju Mekah, sedangkan Rasul dalam keadaan ihrom, beliau berbekam diatas kepala." Dan berkata Al Anshari mengabarkan kepada Hisam bin Hasan : menceritakan kepada kami Ikrimah dari Abbas ra : "Bahwasannya Rasulullah berbekam diatas kepalanya" 6

3. Hadits-hadits yang Berkaitan dengan Waktu yang Baik untuk Bekam

a. Diriwayatkan Tirmidzi dari hadits yang diriwayatkan Ibnu Abbas ra, Rasulullah saw bersabda :

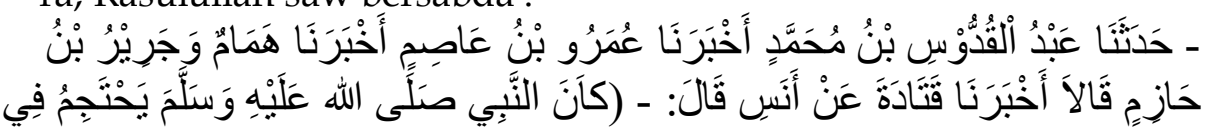

${ }^{4}$ Diriwayatkan oleh Bukhari dalam At Thibb (5357/5356) bab III : Asy syîfấ' fî Tsalatsin, Maktabah Kâmîllah, CD ROOM.

${ }^{5}$ Diriwayatkan oleh Ibn Majah dalam Ath Thibb (3479) bab XX : Al Hijâmah, (Dalam bab tersebut tercantum riwayat Tirmidzi (2059) dari sahabat Abdulloh bin Mas'ud ra. ia berkomentar, "Hadits hasan ghorib." Bushoiri dalam kitab Az Zawaid menulis : Hakim meriwayatkan dalam mustadroknya dari Ibnu Abbas ra, ia berkomentar, "Isnadnya shohih. "diriwayatkan juga oleh Bazzar dalam Musnadnya dari hadits Ibnu Umar ra. hadits ini diperkuat dengan beberapa syawahidnya. Wallohu a'lam.

6 Diriwayatkan oleh Bukhari (no.5373) dalam kitab Ath Thib, bab : al hijâmah 'alâ ro'si. 


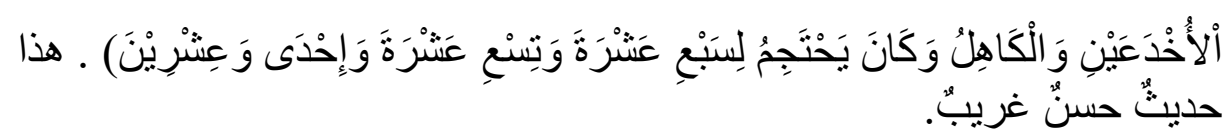

“Abdul Qudus bin Muhammad menceritakan kepada kami,dia berkata Umar bin ashim dan dia berkata Sebaik-baik kalian melakukan bekam adalah pada hari ke- 17,19 atau $21^{\prime \prime} .7$

Dari beberapa kitab dijelaskan bahwasanya hadits-hadits tentang waktu-waktu yang baik dan tidak baik untuk bekam seperti diatas masih terdapat perbedaan pendapat tentang keshohihannya, maka bekam tidak harus diakukan pada tanggal 17, 19 dan 21. Sebab Rasulullah saw pernah melakukan bekam pada saat ihram pada bagian kepalanya karena sakit kepala. Dan, beliau pun tidak menundanya pada waktu lain, misalnya menyelesaikan ihrom dulu. Begitu juga saat beliau keracunan daging kambing, beliau melakukan bekam saat itu juga.

4. Hadits-hadits yang berkaitan dengan manfaat Bekam

a. Diriwayatkan oleh Tirmidzi dalam kitab Sunan no. 2053, Ibnu Majah no. 3478, dan Hakim IV/212 bahwa Rasulullah saw bersabda

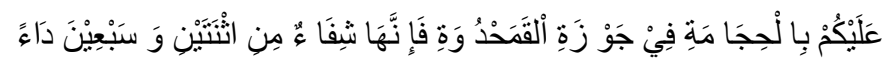

Artinya : "Hendaklah kalian berbekam pada tengah qamahduah karena dapat menyembuhkan 72 penyakit."

\section{PRINSIP-PRINSIP PENGOBATAN RASULULLAH SAW}

1. Keyakinan bahwa Allah SWT yang Maha Penyembuh

Prinsip keyakinan yaitu berkeyakinan bahwa yang menyembuhkan adalah Allah, sehubungan dengan itu dalam merawat pasien hendaknya dengan pelayanan yang baik dan sesuai dengan syariat Islam.

2. Mengunakan Obat Halalan wa Thoyyibah

Prinsip pengobatan dalam Islam yang diajarkan Rasulullah SAW yang kedua adalah bahwa obat yang dikomsumsi harus halal dan baik. Allah SWT yang menurunkan penyakit, maka dialah yang menyembuhkan. Bila kita menginginkan kesembuhan dari Allah SWT maka media ikhtiar (penggunaan obat) kita haruslah media yang diridhoi-Nya. Allah melarang kita memasukan barang yang haram dan merusak ke dalam tubuh kita. Allah berfirman:

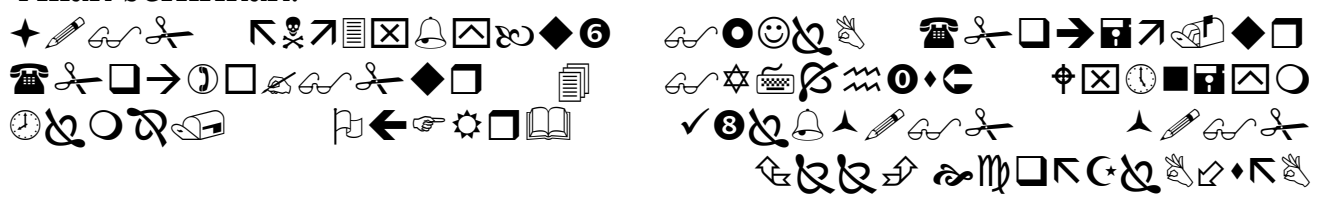

7 Diriwayatkan Turmudzi, kitab at thib (2126) bab 12 Maja'a fil Hijamah 
Artinya: "Dan makanlah makanan yang halal lagi baik dari apa yang Allah telah rezkikan kepadamu, dan bertakwalah kepada Allah yang kamu beriman kepadanya". (QS.Al-Maidah: 88)

Pengunaan obat yang halal disamping mendatangkan ridlo Allah adalah agar supaya badan tetap sehat. Ibnu Qayim dalam bukunya ath Thibb an Nabawi menyatakan:

"Bahwa setiap yang haram bukanlah obat. Karena setiap yang haram tidaklah menyembuhkan melainkan akan mendatangkan penyakit baru yakni penyakit hati".

3. Tidak Menimbulkan Mudharat

Prinsip pengobatan dalam Islam yang ketiga adalah dalam menerapi pasien atau mengkonsumsi obat hendaklah diperhatikan kemudhoratan obat. Seorang dokter muslim akan selalu mempertimbangkan penggunaan obat kepada pasiennya. Untuk penyakit sederhana obatnya adalah obat sederhana (dengan makanan/obat alamiah). Tidak boleh memberikan pasien dengan obat kompleks (obat kimia) sebelum menggunakan obat sederhana dikarenakan obat kompleks bisa memiliki sifat merusak tubuh pasien.

4. Pengobatan tidak Mengandung Unsur TBC (Tahayul, Bid'ah dan Churafat)

Pengobatan yang disyariatkan dalam Islam adalah Pengobatan yang bisa diteliti secara ilmiah. Pengobatan dalam Islam tidak boleh berbau syirik (pergi ke dukun, kuburan, dsb). Allah sendiri selalu memberikan pertolongannya (obat) melalui pengetahuan sebab suatu penyakit.

5. Selalu Mencari yang Lebih Baik (Ikhtiar \& Tawakal)

Islam mengajarkan bahwa dalam berobat hendaklah mencari obat atau dokter yang lebih baik. Dalam etika kedokteran Islam diajarkan bila ada 2 obat yang kualitasnya sama maka pertimbangan kedua yang harus diambil adalah yang lebih efektif dan tidak memiliki efek rusak bagi pasien.

\section{E. SUMBER-SUMBER PENGOBATAN RASULULLAH SAW}

Dari paparan hadits-hadits di atas dapat kita ketahui bahwa sumber pengobatan Rasulullah SAW adalah :

1. Al Qur'an

2. Madu (Obat Alamiah), atau

3. Gabungan Al Qur'an dan obat alamiah

Tiga sumber pengobatan inilah yang utama dan mulia menurut Ibnul Qayim. Beliau mengatakan bahwa ciri pengobatan dalam Islam adalah pengunaan Al Qur'an dan dengan bahan alamiah. Sementara pengobatan alopatik (kimia) tidaklah dikenal dalam pengobatan islam. Pengobatan ini munculnya dari orang-orang Romawi yang digali dengan prinsip sillogisme Al Hijâmah Sebagai Wasilah Dakwah 
atas pendapat Aristoteles, dan Socrates. Sedangkan pengobatan Islam digali atas dasar wahyu. Dengan demikian megikuti wahyu itu lebih pasti dan lebih selamat dari pada mengikuti pendapat manusia. Kebenaran tentang kebaikan/keungulan obat alamiah dibandingkan dengan obat alopatik (kimia) telah ditemukan oleh para ahli medis belakangan ini. Di dalam Convention of Medical Heretic, Robert S. Mendelson, berkata bahwa hampir 100\% antibiotik yg diberikan tidak perlu. Antibiotik hanya boleh diberikan 3-4 kali dalam hidup. Dalam buku Bad Treatment Bad Doctor : penggunaan antibiotik untuk salesme biasa secara berlebihan, mengakibatkan tubuh semakin lemah dan bakteri semakin kuat. Penyakit semakin sukar dirawat, yang berarti risiko maut semakin besar. ${ }^{8}$

\section{F. AL HIJAMAH SEBAGAI WASILAH DAKWAH DALAM MEMBANGUN KESEHATAN UMMAT}

Fisik yang kuat dan sehat merupakan modal utama agar dapat menunaikan tugas dengan baik. Tugas dakwah membutuhkan kemampuan fisik para da'inya begitupun juga mad'unya. Tugas yang penuh tantangan, ancaman, teror, intimidasi dan berbagai tipudaya haruslah ditopang dengan kebugaran tubuh, kekuatan tenaga, ketahanan, ketangkasan, kelincahan dan keuletan adalah keniscayaan bagi kader dakwah demi tegaknya Islam yang kaffah. mereka yang sakit-sakitan cenderung tidak bugar, lemah daya kerjanya akan membebani sesamanya. Ia tidak sanggup memikul beban dakwah yang berat dan panjang. Salah satu dakwah Rasululah yang belum banyak terungkap oleh para da'i yakni dalam masalah kesehatan, yang biasanya hanya dilakukan oleh paramedis tanpa ada unsur-unsur da'awi ataupun unsur ilahiyahnya yang dilakukan kepada pasien.

Dalam agama Islam kesehatan merupakan penjabaran yang nyata dari rahmat kasih sayang Allah yang meliputi segala-galanya dan mamadai risalah Nabi Besar Muhammad SAW, dan itulah sesungguhnya wajah dari Islam. Al hijâmah sebagai wasilah dakwah dalam kesehatan ini mempunyai beberapa aspek dalam pencapainya baik itu dari segi jasadiyah ataupun ruhiyahnya.

1. Dari segi kesehatan jasadiyyah (fisik) dengan kriteria sehatnya fisik yaitu :
a. Tidak merasa sakit dan memang secara klinis tidak sakit.
b. Semua organ tubuh normal dan berfungsi normal.
c. Tidak ada gangguan fungsi tubuh.

2. Sehat mental/jiwa (ruhiyah), mencakup sehat: pikiran, emosional dan spiritual.

a. Bekam Sebagai Wasilah Pembersih Akidah.

Bila memperhatikan pengobatan modern sekarang sungguh banyak yang bertolak belakang dengan prinsip pengobatan Rasulullah SAW.

8 Panduan Intibah I Herba Penwar Al Wahida 
Manusia sekarang banyak beranggapan bahwa obat bisa menyembuhkan penyakit. Keyakinan ini adalah keyakinan yang batil bahkan bisa menjurus kepada syirik. Seorang ulama dari Malaysia $\mathrm{H}$. Ismail bin Ahmad mengungkapkan bahwa rata-rata pasien muslim yang berobat ke rumah sakit, setelah sembuh sakitnya mereka semakin jauh dari Allah SWT dikarenakan mereka memiliki keyakinan yang salah bahwa yang menyembuhkan mereka adalah obat disamping obat-obatan tersebut tidak bisa dipastikan kehalalannya. Sebaliknya, Reasulullah SAW mengajarkan bahwa Allah SWT adalah Dzat Yang Maha Penyembuh. Allah berfirman :

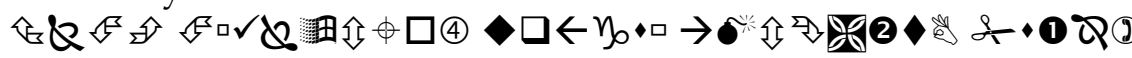

Artinya: "Dan apabila aku sakit, maka Dialah yang menyembuhkan aku." (Asy Syu'ara:80).

Keyakinan ini akan membantu pasien untuk tenang dan dekat kepada Allah yang pada akhirnya akan mempercepat proses kesembuhannya. Itulah sebabnya Rasulullah SAW selalu mengajarkan orang yang sakit untuk berdoa kepada Allah SWT. Dari Nabi Ayyub pun kita bisa mengambil ibroh dari ujian Allah yang ditimpakan Allah kepada beliau, puncaknya adalah ketika beliau menderita penyakit kulit yang sangat parah sampai sanak saudaranya tidak ada yang menjenguknya, hingga istrinyapun tidak sabar dengan penderitaan Nabi Ayyub. Kemudian disaat Nabi Ayyub sendirian, beliau memanjatkan do'a kepada Allah, menyatakan ondisi riil beliau, tanpa ungkapan protes, dan tidak keluar satu patah katapun nada keluhan. Apa yang diungkapakan Nabi Ayyub? Allah SWT berfirman menyatakan kebanggaanya terhadap hambaNya yang luar biasanya ini :

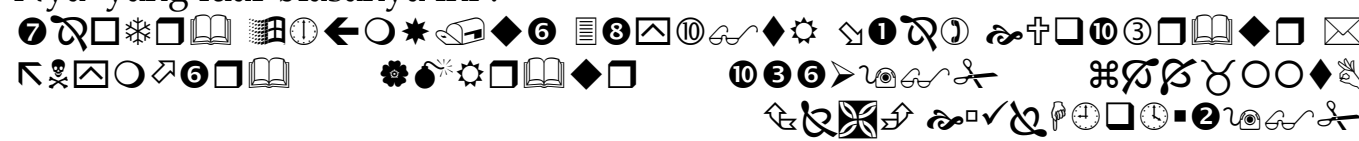

Artinya: "Dan (ingatlah kisah) Ayyub, ketika ia menyeru Tuhannya: "(Ya Tuhanku), Sesungguhnya aku telah ditimpa penyakit dan Engkau adalah Tuhan yang Maha Penyayang di antara semua Penyayang". (Al Anbiya': 83)

Subhanallah yang meluncur dari lisan beliau adalah "Dan Engkau adalah Tuhan yang Maha Penyayang di antara semua Penyayang". Sama sekali tidak terlintas pikiran negatif dibenak Nabi Ayyub meskipun kondisi beliau sangat memprihatinkan. ${ }^{9}$ Betapa banyak orang zaman sekarang ini, disaat segala usaha sudah dilakukan, disaat pengharapan hanya satu-satunya adalah Allah, mereka disembuhkan dengan cara yang tidak mampu dicerna dengan logika dan tidak pernah diteliti oleh dunia kedokteran. Pasien juga diajarkan do'a dan senantiasa mengingat-ingat kalimat Allahu 'Asy Syâfì (Allah Maha Menyembuhkan), baik yang membekam dan hati si pasien dengan keyakianan

${ }^{9}$ Harjani Hefni, The 7 Islamic Daily Habits, Pustaka IKADI; Jakarta, 1430 H/2009 M, cet. IV. hal.129- 
mengenai hal itu..$^{10}$ Do'a yang diajarkan Rasulullah yakni :

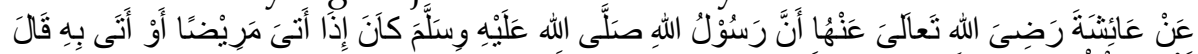

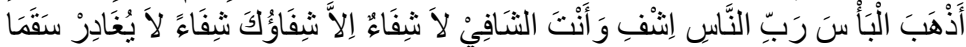
Artinya: "Dari Aisyah ra. Bahwasanya Rasulullah SAW bersabda: "Apabila aku berkunjung kepada orang yang sakit atau ada orang yang sakit datang maka ucapkanlah: "Rabb pemelihara manusia, Ya Allah hilangkanlah penyakit ini dan sembuhkanlah, Engkaulah Yang Maha Penyembuh, tidak ada kesembuhan melainkan kesembuhan dari-Mu, kesembuhan yang tidak meninggalkan sedikitpun penyakit"11

\section{b. Bekam Sebagai Wasilah Perbaikan Ibadah}

Perhatian Rasulullah SAW terhadap masalah kesehatan dan pengobatan penyakit tidak kurang dibanding dengan perhatiannya dalam masalah ibadah. Beliau menaruh perhatian besar terhadap persoalan kesehatan umatnya, karena itu beliau mencontohkan gaya hidup yang sehat dan menganjurkan umatnya untuk segera berobat bila terkena penyakit. Beliau juga menaruh perhatian besar terhadap kesehatan rohani (jiwa) manusia. Nabi SAW menegaskan, "Anda disebut manusia karena jiwanya, bukan karena jasmaninya."12 Tidak disangsikan lagi segi kejiwaan (rohani) dan segi jasmani saling mempengaruhi. Kelemahan yang satu mempengaruhi yang lainnya. Oleh karena itulah Rasulullah mengajarkan kita untuk hidup seimbang, dalam segala hal, termasuk dalam merawat kesehatan. Masalah kesehatan, berkaitan erat dengan ibadah kita, baik ibadah ritual maupun ibadah sosial. Ibadah yang khusus atau pun yang umum. Kesemuanya itu dapat dilaksanakan dengan sempurna apabila kondisi tubuh kita dalam keadaan prima. Apabila badan kita sehat dan fit, Insya Allah kita dapat memenuhi tugas keinsanan dengan sebaik-baiknya. Sebaliknya, ibadah pun ternyata bermanfaat untuk kesehatan kita.

c. Bekam Sebagai Wasilah Perbaikan Akhlaq.

Ada beberapa hal yang harus dilakukan oleh seorang pasien yang akan dibekam, yang nantinya akan memberikan implikasi terhadap perbaikan sifat ataupun pribadi sang pasien tersebut menjadi lebih baik dari pada sebelumnya dengan mengikuti uswah yang telah diberikan Rasul dari segi kesehatan baik itu dari pola maka, pola tidur, pola kehidupannya dalam keseharian dan dari berbagai aspek yang lain. Karena ternyatanya prilaku buruk pada setiap orang akan berdampak negatif bahkan bisa menjadi fatal terhadap kesehatan fisik. Disini penulis akan memaparkan bagaimana prilaku kehidupan Rasul yang

${ }^{10}$ Aiman bin 'Abdul Fattâh, Asy Syifầ' min Wahyi Khôtami 'l-Anbiyâ', Solo: Al Qowam, 2005, h. 244

${ }^{11}$ Diriwayatkan oleh Bukhari (5351) dalam kitab sohih Bukhari jilid II bab kitab maridh.

12 Aby Muhammad Zamry Khadimullah, Hidup Sehat Cara Nabi, www.suaradinamika.com, (download : 07.47 wib, 10 April 2010) 
mulai dari hal-hal terkecil yang ternyata berdampak luar biasa terhadap kesehatan akan tetapi sering kita abaikan, hal-hal tersebut adalah :

1) Cara Makan Rasulullah Shallaahu 'alaihi wasallam Jika kita mengamati pola makan Rasulullah shallallahu alaihi wa sallam. Maka kita akan dapati bahwa beliau mengumpulkan beberapa aspek, diantaranya aspek faidah, kenikmatan dan penjagaan terhadap kesehatan, seperti yang ditetapkan oleh ilmu kedokteran baik dulu maupun sekarang, bahwa mengkonsumsi makanan secara berlebihan akan mengakibatkan berbagai penyakit, dan beliau tidak pernah makan hingga kekenyangan, beliau bersabda:

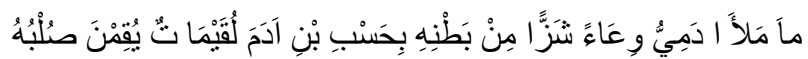

"Cukuplah bagi manusia untuk mengkonsumsi beberapa suap makanan saja untuk menegakkan tulang sulbinya (rusuknya)".

2) Pola Tidur Rasulullah Shallaahu 'alaihi wasallam

Ada beberapa kebiasaan yang dilakukan Rasulullah SAW berkenaan dengan tidur menurut tuntunan beliau yang mungkin kita tidak tahu selama ini namun perlu kita ketahui sekarang agar kita bisa lebih mengenal orang yang paling kita sayangi didunia ini setelah Allah SWT ini, yaitu:

a. Berwudhu dan Berdoa sebelum tidur Tidur.

b. Berdzikir kepada Allah ketika bangun tidur dan menyikat giginya.

c. Rasulullah SAW tidak pernah tidur dalam kondisi perut penuh makanan dan minuman.

d. Rasulullah SAW tidak pernah tidur di atas tanah tanpa alas dan tidak pernah tidur di atas kasur yang terlalu tinggi pula. Minimal beliau memakai kasur yang berisi sabut, menggunakan bantal dan kadangkadang meletakkan tangannya di bawah pipi. ${ }^{13}$

d. Bekam Sebagai Wasilah Dalam Membatasi Ummat dari konspirasi Exsternal

Kedokteran dan kesehatan adalah dua hal yang saling berhubungan. Bak kepingan mata uang, bila seseorang berbicara mengenai salah satu hal tersebut maka yang lainnya takkan bisa dipisahkan. Asumsi inilah yang kemudian membentuk semacam opini miring yang mengatakan bahwa kedua hal tersebut tidak ada hubungan sama sekali dengan agama, terutama Islam. ${ }^{14}$ Hari ini, kiblat pengobatan dunia tertuju pada setidaknya lima jenis metode pengobatan. Lima jenis metode pengobatan yang kini tengah menjadi kiblat pengobatan bagi masyarakat dunia hari ini adalah metode pengobatan modern (alopati), Mistis, Ayurveda, Pengobatan Tradisional China, serta Ath-Thibb AnNabawi.

Sebenarnya, ilmu kedokteran modern atau yang lebih dikenal dengan

13 Syaikh Khalid al Husainan, Tidur yang baik cara Rasulullah, dalam http://www.almanhaj.or.id/content/938/slash/0 (download : 04.00 wib, 17 April 2010)

14 Wasim Fathullah, Tuhfatul Athibbâ' min Kalâmi Khairil Anbiyấ' Al-Arbâ'ûn At-Tibbiyyah, PT Aqwam Medika : Solo, 1430 H/2009.

Al Hijâmah Sebagai Wasilah Dakwah

Dewi Mustika 
istilah alopati (Allophaty) merupakan pengembangan dari ilmu kedokteran Islam yang berkembang sejak abad VIII hijriyah. Karena, acuan ataupun sumber rujukan utama dari alopati adalah Al-Qanun Fii Ath-Thibb (The Canon of Internal Medicine) karangan Ibn Sina (Avicenna). Terlepas dari pro kontra pemikiran filsafat yang diusungnya, Ibn Sina tetap menjadi seorang ilmuwan muslim yang memberikan manfaat cukup besar bagi ilmu kedokteran Islam pada masanya. Sehingga Ibn al-Qayyim al-Jawziyyah yang dalam permasalahan 'aqidah banyak mengkritik Ibn Sina, namun tetap menjadikan Al-Qanun dan Asy-Syifaa' (dua buah kitab kedokteran karya Ibn Sina) sebagai rujukannya saat menyusun kitab ath-Thibb an-Nabawi (Metode Pengobatan Nabi saw.), salah satu bagian dari kitab Zaadul-Maad. Perbedaan yang signifikan antara ilmu kedokteran Islam dengan alopati yang dikembangkan di Barat pasca renaissance adalah pada dua aspek.

Pertama, hilangnya keyakinan bahwa Asy-Syafii' (penyembuh) yang sejati adalah Allah swt.

Kedua, pada obat-obatan atau peralatan medis yang digunakannya. Barat yang sekuler memang sengaja menjauhkan ummat dari ketergantungannya terhadap Al-Khaliq sehingga segala sesuatu yang berkaitan dengan kekuatan Tuhan sering sekali mereka singkirkan. Hal ini membuat ummat terlalu bergantung pada dokter dan obat-obatan saat mereka sakit. Padahal, baik dokter ataupun obat-obatan hanyalah sekedar sebab dan perantara saja, bukan yang menentukan kesembuhan. Ini merupakan sebuah penyakit yang kronis yang hingga kini masih menimpa masyarakat muslim. Dalam pikiran mereka, hal yang pertama kali terlintas saat dirinya ditimpa sakit adalah obat dan dokter. Bukankah ini sebuah kemusyrikan yang nyata?

Sedangkan berkaitan dengan metode pengobatan ataupun obat-obatan yang digunakannya, Barat berupaya untuk mengembangkan ilmu pengetahuan, khususnya pada bidang kedokteran dengan bantuan teknologi. Di satu sisi tentu saja ini merupakan kemajuan yang patut dibanggakan. Proses pengobatan menjadi semakin mudah. Khususnya saat menangani kecelakaan, pemindahan organ tubuh, dan operasi lainnya. Namun di sisi lain, mereka menggunakan bahan-bahan kimia sintetis untuk diracik menjadi obat yang menurutnya dapat menangani berbagai macam penyakit secara instan. Apa benar bahan-bahan kimia merupakan penyembuh..? Atau justru bahan-bahan kimia lah yang menjadi sumber penyakit yang aneh dan baru muncul belakangan..?

\section{G. KESIMPULAN}

Ath-Thibb an-Nabawi yaitu Metode Pengobatan yang dibawa oleh Nabi Muhammad SAW berdasarkan atas wahyu Allah SWT. Maka, metode ini merupakan satu-satunya metode yang diridhai oleh Allah swt dan Rasulullah Muhammad SAW tercinta. Dalam praktiknya, metode kedokteran Islam (Islamic Medicine) atau metode pengobatan Nabi saw. (ath-Thibb an-Nabawi) Al Hijâmah Sebagai Wasilah Dakwah

Dewi Mustika 
mengedepankan aspek alamiah dan ilahiyah yang dibingkai dalam wawasan yang sangat ilmiah. Dua aspek utama (alamiah dan ilahiyah) merupakan tafsir dari hadits Nabi saw. yang berbunyi, "Sesungguhnya pengobatan itu ada dua: madu dan al-Quran." Madu ditafsirkan sebagai bahan-bahan yang alamiah atau biasa disebut dengan obat-obatan herbal. Jadi, tidak hanya terpaku pada satu jenis obat. Sedangkan al-Quran ditafsirkan sebagai metode yang ilahiyah. Artinya bahwa dalam konsep pengobatan Islam atau ath-Thibb an-Nabawi, harus mengedepankan aspek-aspek yang tidak bertentangan dengan syari'at. Ath-Thibb an-Nabawi harus memiliki prinsip yang tegas dalam mempraktikan metode pengobatannya.

Pegobatan yang diajarkan Rasul saw wajib diyakini dan bersifat pasti (qat'ie) bersumberkan wahyu Ilahi. Oleh karena itu, bekam bukanlah sekadar pengobatan alternatif tapi adalah solusi bagi ummat muslim dan sekitarnya, bahkan ini adalah satu kaedah pengubatan yang utama yang wajib diamalkan. Pengobatan bekam merupakan wahyu kerana kaedah ini telah menjadi amalan Rasulullah SAW, tak terkecuali pada seluruh umat yang mengikuti Sunnahnya. Oleh karena ini adalah nasehat tulus yang disampaikan oleh makhlukmakhluk baik nan suci yaitu para penghuni langit untuk penduduk bumi, maka Rasul saw menyampaikan nasehat yang memerintahkan berbekam ini serta mempraktikkannya dengan tindakan dan ucapan, setidaknya seumur hidup sekali bagi kaum muslim untuk berbekam. Berpaling dari mengamalkannya berarti berpaling dari kaedah pengubatan Al-Quran. Pengobatan yang diajarkan Rasul bukanlah menyangkut jasadiyah saja namun lebih diutamakan kepada perbaikan ruhiyah (akidah), perbaikan akhlaq, pola hidup yang sehat yang diajarkan Rasul (ittib'u Rasul) serta kembali kepada Allah As Syafi (Allah yang maha Penyembuh) satu-satunya penyembuh dari segala jenis penyakit dan terhindar jauh dari unsur-unsur TBC (Tahayul, Bid'ah dan Khurofat). ath-Thibb an-Nabawi mengedepankan aspek alamiah dan ilahiyah yang dibingkai dalam wawasan yang sangat ilmiah. Wallahu a'lam.

\section{DAFTAR PUSTAKA}

Abdullah, Shalih bin Fauzan, Kitab at Tauhid Lish shaffits tsalits al Ali, Jakarta; Darul Haq, 1999

Ahmad, Ismail, Buku Panduan Intibah I, Bogaor; PT. Daarusysyifa, 2007

Ahmad, Amrullah, Dakwah Islam dan Perubahan Sosial, Yogyakarta; PLP2M, 1985

Anshari, Endang Saifudin, Wawasan Islam, Jakarta; Rajawali, 1996

Arikunto, Suharsimi, Manajemen Penelitian, Jakarta; Rineka Cipta, 2000

Arifin, Anwar, Strate gi Komunikasi, Bandung; Amico, 1984

Atceh, Abue Bakar, Beberapa Cacatan Mengenai Dakwah Islam, Semarang; Romadoni, 1971

Ar-Rafi'i, Mustofa, Potret Juru Dakwah, Jakarta; Pustaka Al kautsar, 2002 
Arifin, H.M, Psikologi Dakwah, Jakarta ; Bulan Bintang, 1977

Barri, M. Dahlan dan Partono, P.A, Kamus Ilmiah Populer, Surabaya; Arloka, 1998

Habib, M. Syafaat, Buku Pedoman Dakwah, Jakarta; Wijaya, 1992

Hasyimi, A, Dustur Dakwah Menurut Al Qur'an, Jakarta; Bulan BIntang, 1974

Munsy, Abdul Kadir, Metode Diskusi dalm dakwah, Surabaya; Al Ikhlas, 1982

Maliki, Muhammad, Alwi, Syariat Islam Pergumulan Teks dan Realitas, Jogyakarta; eLSQ Press, 2003

Moh, Ali Aziz, Ilmu Dakwah, Kencana ; Jakarta, 2004

Munawwir, A.W, Kamus Al Munawwir, Surabaya, Pustaka Progresif, 1997

Mahfuz, Ali, Hidayat al-Mursyidin ila Thuruq al-Wa'zi wa al-Khitabath, Beirut; Dar al Ma'arif

Mualikah, Mustofa, Manhaj Dakwah DR. Yusuf al Qaradhawi, Jakarta; Pustaka Al Kautsar, 2001

Mulaikah, Mustofa, Manhaj Dakwah Yusuf Al Qoradhowi antara kelembutan dan Ketegasan, Jakarta; Pustaka Al Kautsar, 1997

Mulaikah, Musthafa, Manhaj Dakwah DR. Yusuf al Qaradhawi, Pustaka Al Kutsar; Jakarta, 2001

Muqarror majlis Tarjih Muhammadiyah (HPTM), Jogjakarta; Pimpinan Pusat Muhammadiyah, $1387 \mathrm{H} / 1967 \mathrm{M}$

Natsir, Muhammad, Fiqhu Dakwah, Jakarta; Dewan Islamiyah Indonesia, 1999

Nata, Abudin, Metodelogi Studi Islam, Jakarta; Raja Grafindo Persada, 1998

Nasarudin Latif, Teori dan Praktik Dakwah Islamiyah, Jakarta; Firma Dara, tt

Purwakania, hasan, Alaih B, Pengantar Psikologi Kesehatan Islami, Jakarta;

Rajawali Pres, 2008

Qaradhawi, Yusuf, Anatomi Masyarakat Islam, Pustaka Al Kautsar, 1993

Qaradhawi, Yusuf, Peran Nilai dan Moral dalam Pengembangan Islam, Rabbani Press, 1997

Rahmat, Jalaluddin, Retorika Modern Sebuah Keangkan Teori dan Praktik Berpidato, Bandung; 1982

Sayyid, Muhammad, basith, Abdul, at-Thagdziyah an-Nabawiyah alGhadabaina ad-Daa wa ad-Dawa, Jakarta; Pustaka Almahira, 2006

Shihab, Alwi, Islam Inklusif Menuju Sikap Terbuka dalam Beragama, Bandung; Mian, 1999

Sulaiman bin Shalih Al Khuraisi, Pemikiran DR. Yusuf Al Qaradawi dalam Timbangan, Pustaka As Syafi'i, 2003

Sunardi, dr, Pilih Resep Nabi atau Resep Dokter, Aqwammedika, 2008

Soemargono, Soejono, Filsafat Ilmu Pengetahuan, Yogyakarta; Nur Cahaya, 1983

Solokhin, Abu 'Izzudin, Tarbiyah Dzatiyah, Kiat Sukses Manajemen diri untuk Hidup Lebih Berarti, Solo; Bina Insani Press, 2006

Syihab al-Badri Yasin, Al Hijamah Sunnatun Nabawiyyah wa Mu'jizatun Thibbiyyah, Jakarta; Al Qowam, 2001

Al Hijâmah Sebagai Wasilah Dakwah 
Saifudin, Muhammad Hakim, kemana Seharusnya anda Berobat? Antara Pengobatan Medis, Alternatif dan Thibb Nabawi, Solo; Wacana Ilmiah Pres, 2009

Tasmara, Toto, Komunikasi Dakwah, Jakarta; Gaya Media Pertama, 1997

Umar, Wadda' A, Kesembuhan Dengan Stu Titik, Al Qowam Publishing; Solo, $2009 \mathrm{M} / 1429 \mathrm{H}$

Yafie, Ali, Dakwah dalam Al Qur'an dan As Sunnah, Jakarta; Makalah Seminar, 1992

Yusuf, Soeleman, Slamet Suesanto, Pengantar Pendidikan social, Surabaya ; Usaha Nasional, 1981

Zainuddin, Ahmad, Al Maktabah al-Syamillah CD ROOM, Jakarta, Ridwana Medikita, 2009 